\title{
Is limited-coverage CT perfusion helpful in treatment decision-making in patients with acute ischemic stroke?
}

\author{
Karin Kremenova ${ }^{1}$, Michal Holesta ${ }^{1}$, Tomas Peisker ${ }^{2}$, David Girsa ${ }^{1}$, Jiri Weichet ${ }^{1}$, Jiří Lukavsky $^{3}$, \\ Hana Malikova ${ }^{1,4}$
}

${ }^{1}$ Department of Radiology, Third Faculty of Medicine, Charles University, Faculty Hospital Kralovske Vinohrady, Prague, Czech Rep; ${ }^{2}$ Department of Neurology, Third Faculty of Medicine, Charles University, Faculty Hospital Kralovske Vinohrady, Prague, Czech Rep; ${ }^{3}$ Psychology Department, Faculty of Arts, Charles University, Prague, Czech Rep; ${ }^{4}$ Institute of Anatomy, Second Medical Faculty, Charles University, Prague, Czech Rep

Correspondence to: Hana Malikova. Department of Radiology, Third Faculty of Medicine, Charles University in Prague, Faculty Hospital Kralovske Vinohrady, Srobarova 1150/50, 11000 Prague, Czech Republic. Email: hana.malikova@fnkv.cz.

Background: The initial core infarct volume predicts treatment outcome in patients with acute ischemic stroke (AIS) due to large vessel occlusion (LVO). According to the literature, CT perfusion (CTP) is able to evaluate cerebral parenchymal viability and assess the initial core in AIS. We prospectively studied whether limited-coverage CTP with automated core calculation correlates with the final infarct volume on follow-up non-enhanced CT (NECT) in patients successfully treated by mechanical thrombectomy.

Methods: We enrolled 31 stroke patients (20 women aged $74.4 \pm 12.9$ years and 11 men aged $66 \pm 15.4$ years; median initial NIHSS score 15.5) with occlusion of the medial cerebral artery and/or the internal carotid artery that were treated by successful mechanical thrombectomy. CTP performed in a $38.6 \mathrm{~mm}$ slab at the level of basal ganglia was included in the CT stroke protocol, but was not used to determine indication for mechanical thrombectomy. The infarction core volume based on CTP was automatically calculated using dedicated software with a threshold defined as cerebral blood flow $<30 \%$ of the value in the contralateral healthy hemisphere. The final infarction volume was measured on 24-hour follow-up NECT in the same slab with respect to CTP. Pearson and Spearman correlation coefficients and robust linear regression were used for comparison of both volumes, $\mathrm{P}$ values $<0.05$ were considered as statistically significant.

Results: The median time from stroke onset to CT was 77 minutes (range, 31-284 minutes), and the median time from CT to vessel recanalization was 95 minutes (range, 55-215 minutes). The mean CTPcalculated core infarct volume was $24.3 \pm 19.2 \mathrm{~mL}$ (median $19 \mathrm{~mL}$, range $1-79 \mathrm{~mL}$ ), while the mean final infarct volume was $21.5 \pm 39.5 \mathrm{~mL}$ (median $8 \mathrm{~mL}$; range $0-210 \mathrm{~mL}$ ). Only a weak relationship was found between the CTP-calculated core and final infarct volume $\left[\operatorname{Pr}_{(29)}=0.32, \mathrm{P}=0.078\right.$; rho $\left.=0.40, \mathrm{P}=0.028\right]$. Regression analysis showed CTP significantly overestimated lower volumes.

Conclusions: In our prospective study, the infarction core calculated using limited-coverage CTP only weakly correlated with the final infarction volume measured on 24-hour follow-up NECT; moreover, CTP significantly overestimated lower volumes. Our results do not support the use of limited-coverage CTP for guiding treatment recommendations in patients with AIS.

Keywords: Stroke imaging; perfusion imaging; middle cerebral artery; core; mechanical thrombectomy

Submitted Apr 10, 2020. Accepted for publication Jun 23, 2020.

doi: 10.21037/qims-20-555

View this article at: http://dx.doi.org/10.21037/qims-20-555 


\section{Introduction}

Globally, stroke is the second most common cause of death after ischemic heart disease, with an annual incidence in Europe ranging from 95-290 per 100,000 inhabitants (1). In the Czech Republic, the annual mortality rate of stroke is roughly 56 per 100,000 inhabitants (2). Stroke is also associated with significant long-term disability, affecting up to $50 \%$ of patients $(3,4)$. Long-term disability may be evaluated by various outcome scales, with the modified Rankin Scale (mRS) being commonly used $(3,4)$. The most important risk factors for stroke include diabetes mellitus, hypertension, hypercholesterolemia, age, smoking, and alcohol consumption (3).

Stroke is a generic term that describes a clinical event of sudden-onset neurologic deficit due to vascular occlusion or hemorrhage. Stroke syndromes have significant clinical and pathological heterogenicity, however, arterial ischemia or infarction are by far the most common cause of stroke, accounting for $80-85 \%$ of cases due to impaired blood supply to the brain with subsequent loss of function (5). Roughly $24-46 \%$ of acute ischemic strokes (AIS) are caused by large vessel occlusion (LVO) (6).

Rapid neuroimaging is crucial for the successful therapeutic management of stroke. Routine stroke imaging protocols generally include non-enhanced CT (NECT) and CT angiography (CTA). NECT very quickly answers the first important question in the workup of stroke: is intracranial hemorrhage or a stroke "mimic" present? Once intracranial hemorrhage and stroke mimic are excluded, the next critical question must be answered: is there LVO with a "retrievable" intravascular thrombus present? To answer that question, CTA is the method of choice. CTA can demonstrate not only intravascular thrombus and the site of occlusion, but also collateral blood flow. Additionally, ischemic changes visible on NECT must be evaluated. For the territory of the medial cerebral artery (MCA), the Alberta Stroke Program Early CT score (ASPECTS) is a quick, straightforward and reproducible measure of early ischemic changes. The MCA territory is divided into 10 regions and assigned 1 point per region; ASPECTS is then calculated by subtracting 1 point for each of 10 regions affected (7). ASPECTS $\leq 6$ equates to $\geq 1 / 3$ of the MCA territory and is associated with increased risk of hemorrhage and poor outcome after reperfusion (8). Based on NECT and CTA findings, patients are referred for appropriate therapy. In the case of AIS with LVO, mechanical thrombectomy provides the best clinical outcome $(8,9)$.
Indication criteria for mechanical thrombectomy are the causative occlusion of the internal carotid artery (ICA) or MCA segments $1 / 2$ (M1, M2), age $\geq 18$, ASPECTS $\geq 6$, the National Institute of Health Stroke Scale (NIHSS) $\geq 6$, pre-stroke mRS 0-3 and ideally treatment initiated (groin puncture) within 6 hours from symptomatic stroke onset (9).

CT perfusion (CTP) is an established method used to evaluate the viability of cerebral parenchyma, which is key to acute stroke management. The method has been in use for many years, with controversial results (10). After a period of diminished use, CTP had a resurgence in 2017 following the large multicenter Dawn and Defuse 3 trials, which used the infarction volume (core) and the volume of salvageable tissue (penumbra) calculated from CTP as predictive factors for clinical outcome in patients treated by mechanical thrombectomy $(11,12)$.

We evaluated patients with AIS with LVO that were successfully treated by mechanical thrombectomy. The aim of our prospective study was to evaluate whether limitedcoverage CTP with automated core calculation correlates with the final infarction volume on follow-up NECT in the same volume slab as CTP was performed.

\section{Methods}

\section{Patient selection}

We prospectively included all consecutive patients with AIS, NIHSS $\geq 6$, pre-stroke mRS $0-1$, age $\geq 18$, that underwent initial NECT with ASPECTS $\geq 6$ and CTA-proven LVO (M1 segment of the MCA and/or ICA). Moreover, CTP was performed in all subjects, however CTP was not evaluated in the acute setting and was not used to guide indication for mechanical thrombectomy. All patients underwent technically-successful mechanical thrombectomy, follow-up NECT was performed 24 hours after thrombectomy.

The study was approved by the Ethics committee of Faculty Hospital Kralovske Vinohrady, Prague, Czech Republic. Signed, informed consent was provided by all patients to participate in the study. The study was initiated in January 2019 and terminated early in August 2019 due to preliminary results.

\section{CT imaging}

All examinations were performed on a 128 -slice CT scanner (Definition AS+, Siemens, Erlangen, Germany). Initially, before treatment, all patients underwent NECT 
Table 1 Acquisition and reconstruction parameters of non-enhanced CT, CT angiography and CT perfusion

\begin{tabular}{|c|c|c|c|}
\hline Parameter & NECT & CTA & CTP \\
\hline Tube voltage (kVp) & 120 & 100 & 80 \\
\hline Tube current (mA) & 350 & 175 & 270 \\
\hline Gantry tilt & yes & no & yes \\
\hline Iterative reconstruction & Yes^$^{\wedge}$ & Yes^$^{\wedge}$ & No \\
\hline Reconstruction filter/kernel & Soft tissue & Soft tissue & Soft tissue \\
\hline Primary reconstruction slice thickness/increment $(\mathrm{mm})$ & $3 / 3$ & $0.75 / 0.5$ & $3 / 3$ \\
\hline Multiplanar reconstruction (slice/increment mm) & $\begin{array}{c}\text { 4/4 transversal, coronal, } \\
\text { sagittal }\end{array}$ & $3 / 3$ transversal, sagittal & $a$ \\
\hline Contrast volume $(\mathrm{mL})$ & - & 60 & 50 \\
\hline Injection rate $(\mathrm{mL} / \mathrm{s})$ & - & 5 & 6 \\
\hline Z-axis coverage & Whole brain & From aortic arch to vertex & $38.6 \mathrm{~mm}$ \\
\hline
\end{tabular}

and CTA followed by CTP. Acquisition and reconstruction parameters for NECT, CTA and CTP are summarized in Table 1.

\section{Imaging analysis and evaluation}

All image analyses and measurements were performed using Syngo.via software (Siemens Healthineers). CTP was performed in a limited volume slab $(38.6 \mathrm{~mm}$ in the z-axis) only at the level of the basal ganglia. The ischemic core was automatically calculated on CTP by dedicated software. The core was defined as an area with cerebral blood flow $(\mathrm{CBF})<30 \%$ of $\mathrm{CBF}$ in the contralateral healthy hemisphere. The penumbra was defined as an area with a time to maximum (TMAX) over 6 seconds. TMAX was defined as the time from inflow of an intraarterial contrast agent to the area of interest to the peak density in the area.

Definitive infarction on 24-hour follow-up NECT was defined as a visible hypodense area with indistinct graywhite matter borders. The volume of definitive infarction was manually segmented using $1.5 \mathrm{~mm}$ slices. This manual segmentation was performed only in the same volume (38.6 $\mathrm{mm}$ in the z-axis) as CTP was performed. All manual segmentations and measurements were performed using Syngo.via software by one radiologist, who was blinded to the initial automatic measurement results.

\section{Statistics}

Data were expressed as mean $\pm \mathrm{SD}$ and median. We report both Pearson and Spearman correlation coefficients to describe the relationship between the core volume calculated on CTP and the final infarct volume measured on follow-up NECT, 24 hours after initial imaging. Robust linear regression (13) was used to model the relationship between the core volume calculated on CTP (dependent variable) and the final infarct volume measured on NECT (predictor), where we report parameter confidence intervals. The Mann-Whitney $U$ test was used to compare differences between patient groups, based on CTP and followup NECT volumetric differences. $\mathrm{P}$ values $<0.05$ were considered as statistically significant.

We additionally included all participants fulfilling the inclusion criteria in a post-hoc power analysis. While the sample size appears low, the two methods need to be very highly correlated to be useful in clinical settings. Even if we 
Table 2 Patient selection and demographic data (31 subjects; 20 females, 11 males)

\begin{tabular}{lccccc}
\hline Parameters & Mean & Median & SD & Minimum & Maximum \\
\hline Age (years) & 72.1 & 72 & 13.7 & 41 & 96 \\
Age female (years) & 74.4 & 77 & 10 & 49 & 96 \\
Age male (years) & 66 & 62 & 15.4 & 41 & 92 \\
NIHSS & 14.5 & 15.5 & 6.5 & 6 & 30 \\
ASPECTS & 8 & 8 & 1.3 & 6 & 10 \\
Time from stroke onset to CT (minutes) & 95 & 77 & 57.5 & 31 & 284 \\
Time from CT to mechanical recanalization (minutes) & 107.5 & 95 & 43 & 55 & 215 \\
\hline
\end{tabular}

ASPECTS, Alberta Stroke Program Early CT score; CT, computed tomography; CTA, CT angiography; CTP, CT perfusion; NECT, non-enhanced CT; NIHSS, National Institute of Health Stroke Scale; SD, standard deviation.

assume conservatively that $\mathrm{r}=0.80$ would be sufficient, the achieved power is very high: power $=0.999$ for alpha $=0.05$ and $\mathrm{N}=31$.

\section{Results}

\section{Patient selection}

Thirty-one subjects (20 females, 11 males) fulfilled all inclusion criteria and were enrolled in the study. Eighteen subjects received additional bridging intravenous thrombolysis before mechanical thrombectomy. The median NIHSS score of included subjects was 15.5. The median time from stroke onset to CT was 77 minutes (range, 31-284 minutes), while the median time from CT examinations to vessel recanalization was 95 minutes (range, 55-215 minutes). Selection and demographic data of all included subjects are summarized in Table 2.

\section{Volume measurements and statistics}

The volume of the ischemic core (38.6 mm slab in the $\mathrm{z}$-axis) according to the above-described automatic calculation was mean $24.3 \pm 19.2 \mathrm{~mL}$ (median $19 \mathrm{~mL}$, range, $1-79 \mathrm{~mL}$ ). The final infarction volume on 24-hour follow-up NECT measured in the same slab was mean $21.5 \pm 39.5 \mathrm{~mL}$ (median $8 \mathrm{~mL}$, range $0-210 \mathrm{~mL}$ ).

We found a weak relationship between CTP and follow-up NECT core measurements $\left[\mathrm{r}_{(29)}=0.32, \mathrm{P}=0.078\right.$; Spearman rho $=0.40, \mathrm{P}=0.028]$. Even for Spearman rho, the bootstrapped $95 \%$ confidence interval (0.00-0.71) showed the correlation coefficient was substantially lower than we expected from the two measurements. As our sample primarily contained patients with low values in both measurements, and patients with large values (especially in the final infarct volume) could constitute outliers, we used robust linear regression to evaluate the nature of the relationship. We tested a linear regression model predicting perfusion measurements from final infarct volume measurements (V_perfusion $=\mathrm{a}+\mathrm{b}{ }^{*} V_{-}$core $)$. We found that CTP significantly overestimated lower values (estimated parameter $\mathrm{a}=12.4 ; 95 \%$ confidence interval 8.6-16.1), and its values change slower with higher core values $(b=0.55$; $95 \%$ confidence interval $0.45-0.64)$. The association is demonstrated in Figure 1.

Subjects were further divided into 3 subgroups according to the difference between the initial core volume calculated by CTP and the volume of final infarct manually measured on follow-up NECT (CTP core volume minus the final infarct volume on follow-up NECT), with cut-off values of $10 \mathrm{~mL}$. In subgroup 1, which consisted of $6(19 \%)$ patients, the final infarct volume was underestimated by more than $10 \mathrm{~mL}$ using CTP (Figure 2). Subgroup 2 consisted of 12 patients and had $\pm 10 \mathrm{~mL}$ volumetric differences. In the remaining 13 patients (42\%) in subgroup 3, the final infarct volume was overestimated by more than $10 \mathrm{~mL}$ using CTP (Figure $3 A, B$ ). In subgroup 3 , in comparison with subgroups 1 and 2, a shorter time from CT to recanalization was found; however, no differences in times from stroke onset to $\mathrm{CT}$ and from CT to recanalization were significant (all $\mathrm{P}>0.05)$. For further details see Table 3.

\section{Discussion}

The purpose of our study was to evaluate whether initial CTP can accurately predict the final infarct volume in 


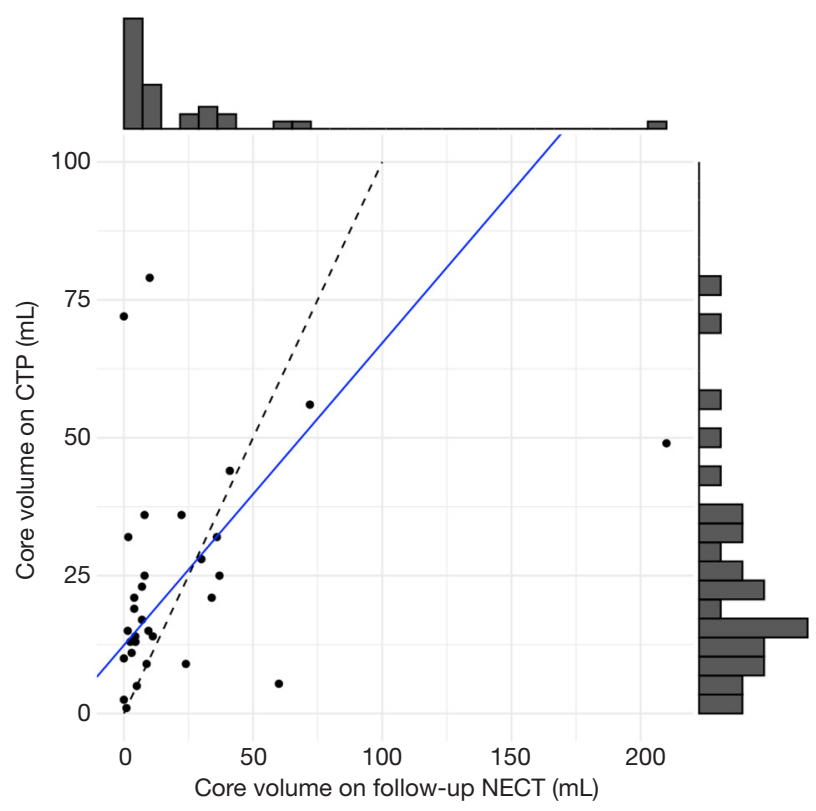

Figure 1 Correlation of ischemic core volume on CT perfusion with definitive infarct volume measured on non-enhanced follow-up CT. The dashed line represents the identity of both measurements and the blue line represents the regression line. The marginal plots depict the distribution of the volume data. patients treated by successful mechanical thrombectomy. We compared the initial core volume automatically calculated from CTP and the final infarct volume manually measured on 24-hour follow-up NECT. All patients suffered from AIS due to occlusion of the MCA (the M1 segment) and/or the ICA and fulfilled indication criteria for mechanical thrombectomy (9). Mechanical thrombectomy was indicated regardless of CTP results; CTP data were evaluated separately at a later time using dedicated, automated software.

We found only a weak correlation between the initial CTP-measured core and the final infarct volume. However, we found CTP significantly overestimated lower volumes. We conclude that CTP performed in a $38.6 \mathrm{~mm}$ volume slab is not a suitable method for the selection of patients for interventional treatment, as according to our data, several patients that profited from mechanical thrombectomy would have been excluded from interventional treatment based on CTP results. Therefore, the study was terminated early; we did not detect any benefit to exposing our patients to a higher radiation dose in performing CTP. Moreover, additional CTP scans required double administration of an iodine-based contrast agent that poses risks for renal
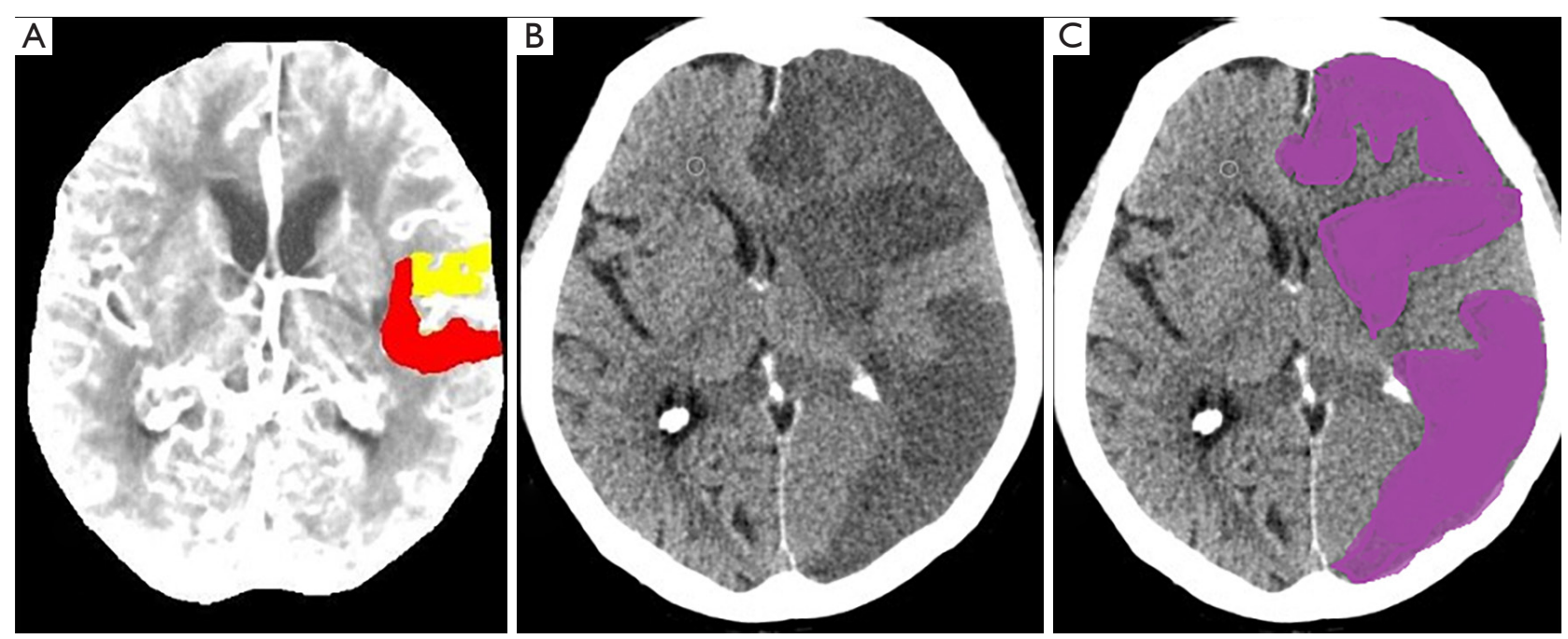

Figure 2 Underestimation of infarct core volume on CT perfusion map. CT perfusion map (A) obtained initially before mechanical thrombectomy depicts core (red) and penumbra (yellow). Non-enhanced follow-up CT (B) depicts large final infarct (purple) in the left hemisphere $(\mathrm{C})$. 


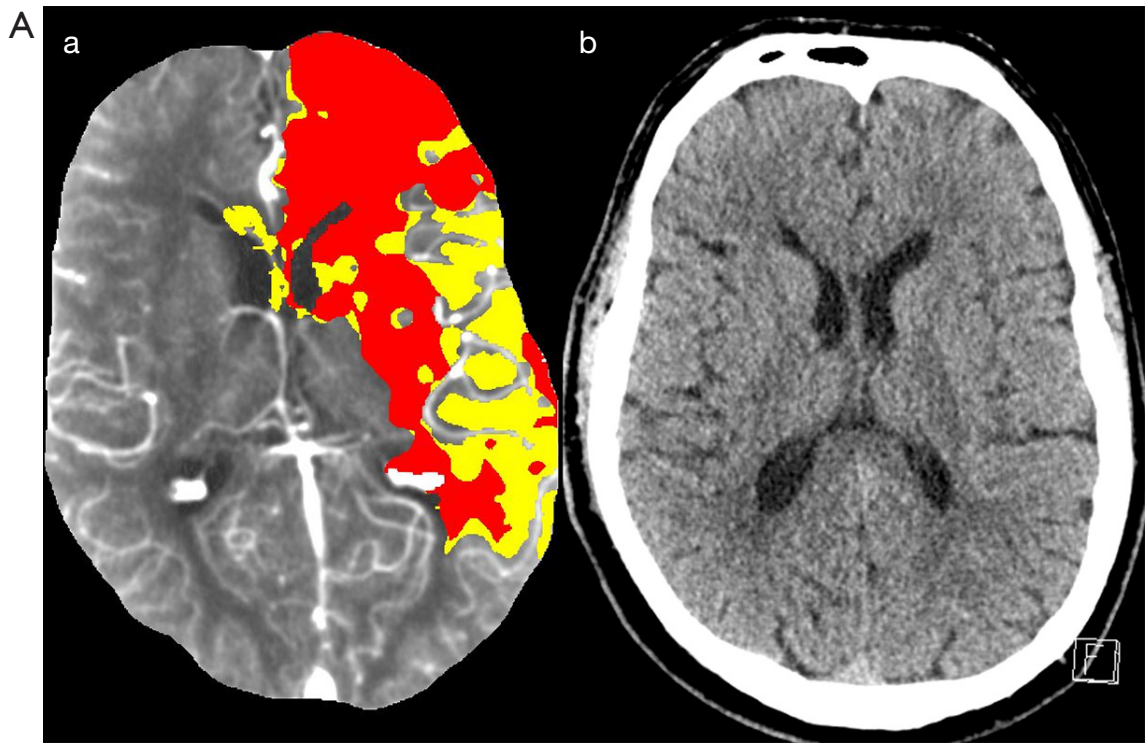

B a

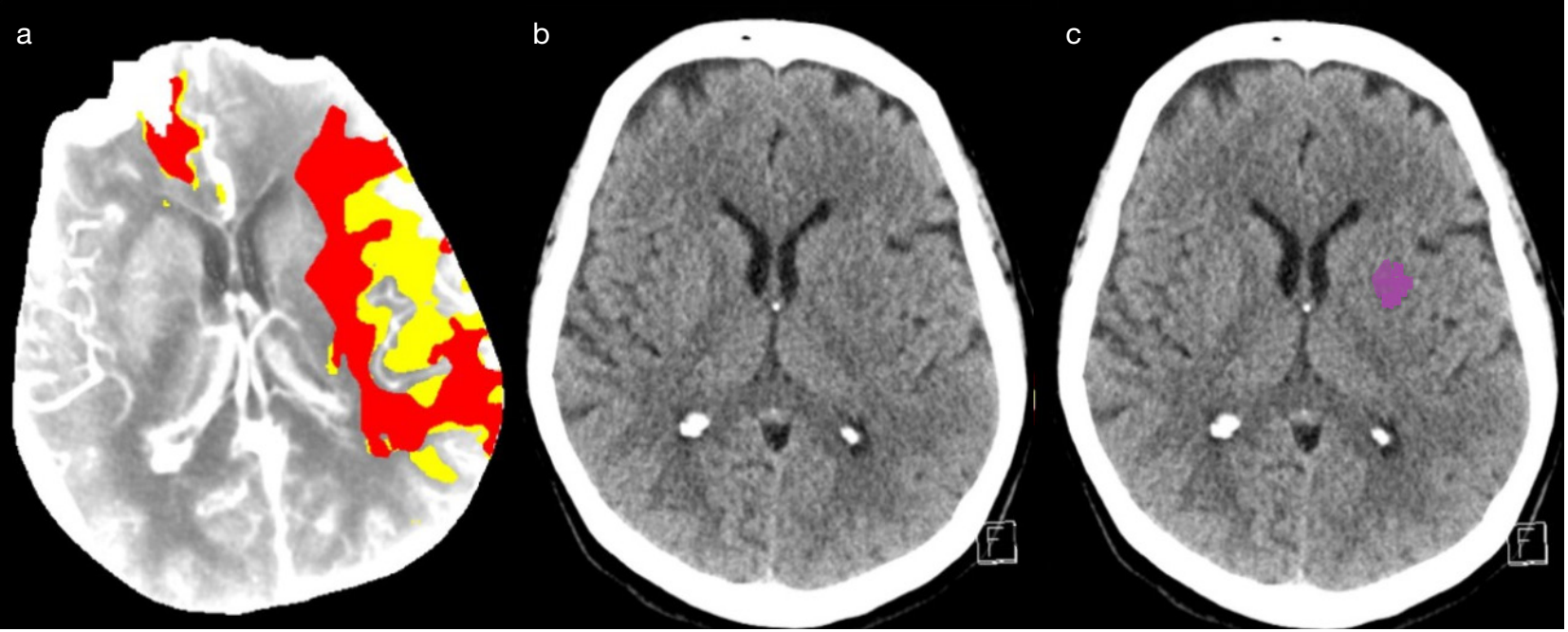

Figure 3 Overestimation of infarct core volume on CT perfusion map. (A) CT perfusion map (a) obtained initially before mechanical thrombectomy depicts core (red) and penumbra (yellow). Non-enhanced follow-up CT (b) is without unambiguous infarct. (B) CT perfusion map (a) obtained initially before mechanical thrombectomy depicts core (red) and penumbra (yellow). Non-enhanced follow-up CT (b) demonstrates overestimation of the core volume by CT Perfusion. Non-enhanced CT depicts only small infarct (purple) in the left basal ganglia (c).

function decline, especially in elderly patients.

Our findings are in concordance with a study by Tsang et al. [2018] (14), who reported a poor correlation between the CTP ischemic core volume and the volume of definitive infarction on 24-hour follow-up NECT. They included 86 patients with a mean age of 70 years with LVO that underwent successful mechanical thrombectomy. In contrast to the present study, they performed whole brain CTP, as opposed to limited coverage. Similar results were also published in a study by Geuskens et al. (15), who similarly included a relatively small number of patients $(n=35)$. However, they used more than $100 \mathrm{~mm}$ brain coverage CTP and the final infarct volume was measured on 5-7-day follow-up NECT.

Some recent studies have reported overestimation of the final infarct volume by initial CTP, and the term ghost infarct core (GIC) has been established $(16,17)$. GIC is defined as the CTP initial core volume minus the final 
Table 3 Characteristics of patient subgroups based on volume differences on CT perfusion and non-enhanced follow-up CT

\begin{tabular}{|c|c|c|c|}
\hline Core volumes on CTP minus infarct volumes on follow-up NECT (mL) & Subgroup $1(<-10)$ & Subgroup $2(-10-10)$ & Subgroup $3(>10)$ \\
\hline Time from stroke onset to CT (minutes) & $77 \pm 42$ & $121 \pm 78$ & $79 \pm 30$ \\
\hline Time from CT to mechanical recanalization (minutes) & $133 \pm 55$ & $114 \pm 44$ & $88 \pm 27$ \\
\hline Core volumes on CTP $(\mathrm{mL})$ & $27.6 \pm 20.8$ & $15.7 \pm 12.8$ & $30.6 \pm 21.6$ \\
\hline
\end{tabular}

Data are reported as mean values \pm standard deviation. CT, computed tomography; CTP, CT perfusion; NECT, non-enhanced CT.

infarct volume on NECT $>10 \mathrm{~mL}$ and has been observed especially in patients imaged within a short time frame (from stroke onset to CT) with fast and complete recanalization $(16,17)$. Martins et al. (16), in their retrospective singlecenter study, reported GIC phenomenon in 20 (16\%) of 123 patients. The GIC phenomenon was associated with a short time frame to recanalization (150 minutes) and a larger initial CBF core volume $(38 \mathrm{~mL})$. In another study by Boned et al. (17), 79 patients were included, 30 (38\%) of which fulfilled criteria for the GIC phenomenon. The subjects underwent CTP in an early time frame from symptomatic stroke onset; the mean time from stroke onset to CTP was 165 minutes, and the mean time from CTP to recanalization was 136 minutes. In the present study, all subjects were divided into 3 subgroups according to differences between the final infarct volume and the core volume on CTP, using a threshold of $10 \mathrm{~mL}$. The core volume on CTP overestimated the final infarct volume more than $10 \mathrm{~mL}$ in 13 subjects, which we consider GIC phenomenon. The time frame from CT to recanalization in this subgroup was shorter than in the rest of subjects, although not significant probably due to limited sample size. We must stress the fact that we used limited-coverage CTP and were able to assess the core volume and the final infarct volume only in a $38.6 \mathrm{~mm}$ slab at the level of basal ganglia. Thus, our results are not entirely comparable with the results of previous studies. However, our study and the above-mentioned studies suggest that therapy guidance based on the CTP-calculated core volume could lead to the incorrect exclusion of some patients that would benefit from mechanical thrombectomy.

An alternative imaging method to NECT and CTP is magnetic resonance imaging (MRI) with diffusion weighted imaging (DWI), which can reliably identify ischemic areas affected by cytotoxic edema within several minutes after stroke onset. According to recommendations and guidelines of the American Academy of Neurology [2010], MRI with DWI should be performed for the most accurate diagnosis of AIS (18). However, there is emerging evidence that DWI fails to identify AIS in a substantial minority of patients. According to a meta-analysis by Edlow et al. published in 2017 (19), the pooled prevalence of DWI-negative AIS was $6.8 \%$. Neurologic deficits consistent with posterior circulation ischemia were significantly associated with DWI-negative AIS, as patients with posterior circulation ischemia were 5 times more likely than patients with anterior circulation ischemia to present with a negative DWI scan. According to the above-mentioned results, MRI with DWI is a reliable method for acute ischemia/infarct assessment in the MCA territory. However, the findings of Edlow et al. suggest that AIS should remain a clinical diagnosis and clinicians should not exclude patients from reperfusion therapies based on a negative DWI scan.

Our study has several important limitations. First, it was a single center study. Another very important limitation was performing CTP only in a $38.6 \mathrm{~mm}$ (z-axis) slab of the brain due to technical limitations of our CT scanner. Another limitation was the measurement of the final infarct volume on NECT, measurement of the definitive infarct volume on MRI would likely be more precise. Moreover, all volumetric measurements were performed by a single radiologist, and the study had a limited number of subjects due to early termination.

\section{Conclusions}

In the present prospective study, the ischemic core calculated using limited-coverage CTP only weakly correlated with the final infarction volume measured on 24-hour follow-up NECT; most importantly, CTP significantly overestimated lower volumes. This led to the early termination of the study. Our results suggest that 
using limited-coverage CTP for the selection of patients for interventional treatment is not justified, considering additional radiation burden and risk associated with double iodine-based contrast media applications.

\section{Acknowledgments}

Funding: This study was supported by the Czech government research program INTERCARDIS, Reg. č. CZ.02.1.01/0.0/0.0/16_026/0008388 and by the Charles University research program PROGRES Q28.

\section{Footnote}

Availability of Data and Materials: Data and materials are presented in the main body of the article and in supplemental tables. The raw imaging data and clinical data are stored digitally at Faculty Hospital Kralovske Vinohrady Prague, Czech Republic.

Conflicts of Interest: All authors have completed the ICMJE uniform disclosure form (available at http://dx.doi. org/10.21037/qims-20-555). MH serves as an unpaid editorial board member of Quantitative Imaging in Medicine and Surgery. The other authors have no conflict of interests to declare.

Ethical Statement: This study conforms to the Declaration of Helsinki. The study was part of the PRAGUE-16 study and was approved by the Ethics committee of Faculty Hospital Kralovske Vinohrady, Prague, Czech Republic. Signed, informed consent was provided by all patients.

Open Access Statement: This is an Open Access article distributed in accordance with the Creative Commons Attribution-NonCommercial-NoDerivs 4.0 International License (CC BY-NC-ND 4.0), which permits the noncommercial replication and distribution of the article with the strict proviso that no changes or edits are made and the original work is properly cited (including links to both the formal publication through the relevant DOI and the license). See: https://creativecommons.org/licenses/by-nc-nd/4.0/.

\section{References}

1. Béjot Y, Bailly H, Durier J, Giroud M. Epidemiology of stroke in Europe and trends for the 21st century. La Presse Médicale 2016;45:e391-8.
2. Institute of Health Information and Statistics of the Czech Republic. Available online: https://reporting.uzis.cz/cr/ index.php?pg=statisticke-vystupy--ukazatele-zdravotnihostavu--dalsi-onemocneni--mozkova-mrtvice (accessed 28th February 2020).

3. Donkor ES. Stroke in the 21st Century: A Snapshot of the Burden, Epidemiology, and Quality of Life. Stroke Res Treat 2018;2018:3238165.

4. Broderick JP, Adeoye O, Elm J. Evolution of the Modified Rankin Scale and Its Use in Future Stroke Trials. Stroke 2017;48:2007-12.

5. Chen CY, Li CW, Mak HK, Lin MF, Chan WP. Combined native magnetic resonance angiography, flow-quantifying, and perfusion-imaging for impending second stroke assessment. Quant Imaging Med Surg 2019;9:521-9.

6. Rennert RC, Wali AR, Steinberg JA, Santiago-Dieppa DR, Olson SE, Pannell JS, Khalessi AA. Epidemiology, Natural History, and Clinical Presentation of Large Vessel Ischemic Stroke. Neurosurgery 2019;85:S4-8.

7. Pexman JH, Barber PA, Hill MD, Sevick RJ, Demchuk AM, Hudon ME, Hu WY, Buchan AM. Use of the Alberta Stroke Program Early CT Score (ASPECTS) for Assessing CT Scans in Patients with Acute Stroke. AJNR Am J Neuroradiol 2001;22:1534-42.

8. Zivelonghi C, Tamburin S. Mechanical thrombectomy for acute ischemic stroke: the therapeutic window is larger but still time is brain. Funct Neurol 2018;33:5-6.

9. Powers WJ, Rabinstein AA, Ackerson T, Adeoye OM, Bambakidis NC, Becker K, Biller J, Brown M, Demaerschalk BM, Hoh B, Jauch EC, Kidwell CS, Leslie-Mazwi TM, Ovbiagele B, Scott PA, Sheth KN, Southerland AM, Summers DV, Tirschwell DL; American Heart Association Stroke Council. 2018 Guidelines for the Early Management of Patients With Acute Ischemic Stroke: A Guideline for Healthcare Professionals From the American Heart Association/American Stroke Association. Stroke 2018;49:e46-110.

10. Mazzei MA, Preda L, Cianfoni A, Volterrani L. CT perfusion: technical developments and current and future applications. Biomed Res Int 2015;2015:397521.

11. Albers GW, Lansberg MG, Kemp S, Tsai JP, Lavori P, Christensen S, Mlynash M, Kim S, Hamilton S, Yeatts SD, Palesch Y, Bammer R, Broderick J, Marks MP. A multicenter randomized controlled trial of endovascular therapy following imaging evaluation for ischemic stroke (DEFUSE 3). Int J Stroke 2017;12:896-905.

12. Jovin TG, Ribo M, Pereira V, Furlan A, Bonafe A, Baxter B, 
Gupta R, Lopes D, Jansen O, Smith W, Gress D, Hetts S, Lewis RJ, Shields R, Berry SM, Graves TL, Malisch T, Rai A, Sheth KN, Liebeskind DS, Nogueira RG. Diffusionweighted imaging or computerized tomography perfusion assessment with clinical mismatch in the triage of wake up and late presenting strokes undergoing neurointervention with Trevo (DAWN) trial methods. Int J Stroke 2017;12:641-52.

13. Wang J, Zamar R, Marazzi A, Yohai V, Salibian-Barrera M, Maronna R, Zivot E, Rocke D, Martin D, Maechler M, Konis K. (2020). robust: Port of the S+ "Robust Library". R package version 0.5-0.0. Available online: https:// CRAN.R-project.org/package=robust

14. Tsang ACO, Lenck S, Hilditch C, Nicholson P, Brinjikji W, Krings T, Pereira VM, Silver FL, Schaafsma JD. Automated CT Perfusion Imaging Versus Non-contrast CT for Ischemic Core Assessment in Large Vessel Occlusion. Clin Neuroradiol 2020;30:109-14.

15. Geuskens RREG, Borst J, Lucas M, Boers AMM, Berkhemer OA, Roos YBWEM, van Walderveen MAA, Jenniskens SFM, van Zwam WH, Dippel DWJ, Majoie CMLM, Marquering HA. Characteristics of Misclassified CT Perfusion Ischemic Core in Patients with Acute Ischemic Stroke. PLoS One 2015;10:e0141571.

16. Martins N, Aires A, Mendez B, Boned S, Rubiera M,

Cite this article as: Kremenova K, Holesta M, Peisker T, Girsa D, Weichet J, Lukavsky J, Malikova H. Is limitedcoverage CT perfusion helpful in treatment decision-making in patients with acute ischemic stroke? Quant Imaging Med Surg 2020;10(10):1908-1916. doi: 10.21037/qims-20-555
Tomasello A, Coscojuela P, Hernandez D, Muchada M, Rodríguez-Luna D, Rodríguez N, Juega JM, Pagola J, Molina CA, Ribó M. Ghost Infarct Core and Admission Computed Tomography Perfusion: Redefining the Role of Neuroimaging in Acute Ischemic Stroke. Interv Neurol 2018;7:513-21.

17. Boned S, Padroni M, Rubiera M, Tomasello A, Coscojuela P, Romero N, Muchada M, Rodríguez-Luna D, Flores A, Rodríguez N, Juega J, Pagola J, Alvarez-Sabin J, Molina CA, Ribó M. Admission CT perfusion may overestimate initial infarct core: the ghost infarct core concept. J Neurointerv Surg 2017;9:66-9.

18. Schellinger PD, Bryan RN, Caplan LR, Detre JA, Edelman RR, Jaigobin C, Kidwell CS, Mohr JP, Sloan M, Sorensen AG, Warach S; Therapeutics and Technology Assessment Subcommittee of the American Academy of Neurology. Evidence-based guideline: The role of diffusion and perfusion MRI for the diagnosis of acute ischemic stroke: report of the Therapeutics and Technology Assessment Subcommittee of the American Academy of Neurology. Neurology 2010;75:177-85.

19. Edlow BL, Hurwitz S, Edlow JA. Diagnosis of DWInegative acute ischemic stroke. A meta-analysis. Neurology 2017;89:256-62. 